\title{
The CBE Education Mode and Construction of Serial Courses on 'Fundamentals of Machinery Manufacture’
}

\author{
Haiguo Ren \\ The School of Electromechanical Engineering \\ Northwestern Polytechnical University \\ Xi'an, China \\ rhglql@nwpu.edu.cn
}

\begin{abstract}
To meet the requirement of talent cultivation in the $21^{\text {st }}$ century, it is necessary to reform the current teaching-learning system for 'Fundamentals of Machinery Manufacture'. How to guide course reformation with advanced education theories is a subject of great importance to be addressed. In this article, the author proposes utilizing the CBE educational mode to guide multifaceted courses construction on 'Fundamentals of Machinery Manufacture', including investigation and analysis of the market, determination of cultivation goals, establishment of the 'study package' as well as how to execute the reformed teaching contents.
\end{abstract}

Keywords-CBE education; Fundamentals of Machinery Manufacture; Educational Reformation

\section{INTRODUCTION}

The program 'Towards the 21st Century - Reshaping the Teaching/Learning Contents and Curriculum Planning', initiated and managed by the State Ministry of Education of China, demands updating the concept of education, changing the mode of talent cultivation as well as setting up new teaching/learning contents and curriculum planning so as to adapt them to the needs of cultivating higher level talents in the 21st century. How to apply advanced educational concepts to courses construction thus becomes an issue of great importance for reformation of higher education [1-2].

During the past few years, the Competency Based Education (CBE) mode [3-6] that focuses on occupational training has become internationally popular. Instead of the monotonous old mode of disciplinary construction, the CBE mode makes education plans based on both the competence of students and the actual requirements of employers. Besides, the CBE mode takes advantage of various forms of media and utilizes flexible tutoring manners, and its teaching contents mainly focus on operation skills, so the goal of cultivation is not only clear but also practical. Obviously, the CBE mode is distinctive from others in that it is based on the nature of students and exaggerates the usefulness of what is being taught. The serial courses involved in 'Fundamentals of Machinery Manufacture' include all aspects from class learning to experiments and to actual practice, and together these constitute the only set of courses that offers students systematic training in engineering. The traditional serial courses composed of 'Mechanical Engineering Materials', 'Practice of
Metal Processing' and 'Metallurgical Technology' are now out of the date and fall far beyond the state of the art, so it is impossible to continuing using them to cultivate talents that have high level complex skills. So, advanced educational concepts have to be explored to set up a new curriculum for 'Fundamentals of Machinery Manufacture', so as to meet the requirement of education reformation.

Here I propose that the CBE theory can be employed to direct curriculum planning for Fundamentals of Machinery Manufacture [7-8], compiling of the syllabus, preparing the learning materials, and determining the examination manner as well as establishing the ultimate cultivation goals. These issues together constitute a systematic program and a huge project, though, by employing the elementary constituents of the CBE education mode, we can divide this huge project into smaller ones and individually study them.

\section{Market InVEstigation And Establishment OF NEW CULTIVATION GOALS}

The modern sciences and technologies are progressing extremely fast, also the actual needs of the society constantly change, so the educational mode and the cultivation goals must be directed by and dynamically follow the market demands. Establishment of the serial courses involved in Fundamentals of Machinery Manufacture thus must be done after thorough investigation of the qualities and skills that employers are seeking for from employees. After all, usefulness is the ultimate goal of education, instead of a show.

\section{A. Understanding the Requirement of the Society for Machinery Manufacture Talents}

The serial courses on fundamentals of machinery manufacture are obligatory courses for engineering students during their advanced education. Although they have different majors and cultivation directions, the courses they are given are very similar and do not manifest their different backgrounds. It is urgent to investigate the different requirements among different majors and cultivation directions, the hiring status of graduates and the major machinery manufacture problems they are facing, and what the employers are thinking of and seeking for from the newly employed graduates, so the advanced education system can purposefully adjust its teaching contents and training processes. 


\section{B. Optimize the Goals of Course Teaching and Strengthen the Students' Awareness of Engineering}

The goals of course teaching include the overall goals, the stage goals, and the chapter goals. The overall goals can be regarded as a tree trunk, while the stage and chapter goals are more like branches and leaves, combined together, they form the knowledge tree. Strengthening the awareness of engineering must be exaggerated in the whole process of course teaching, and serial courses must be holistic, useful and advanced.

Being holistic means that the courses such as 'Engineering Materials', 'Material Molding Technology' and 'Machinery
Manufacture Technology' should be closely combined with 'Practice of Metal Processing', and the course contents being taught must be based on the needs of actual applications, so theories and actual practice can be integrated together. Being useful means combination of basic operation with theories, as well as combination of field teaching, skill training, lectures with class discussion. Being advanced means combination of traditional techniques with current high technologies, which tightly follows the industry development direction of integrating electronics, mechanics and computer control. Newly developed promising and mature enough technics and crafts should be the focus of teaching and practicing.

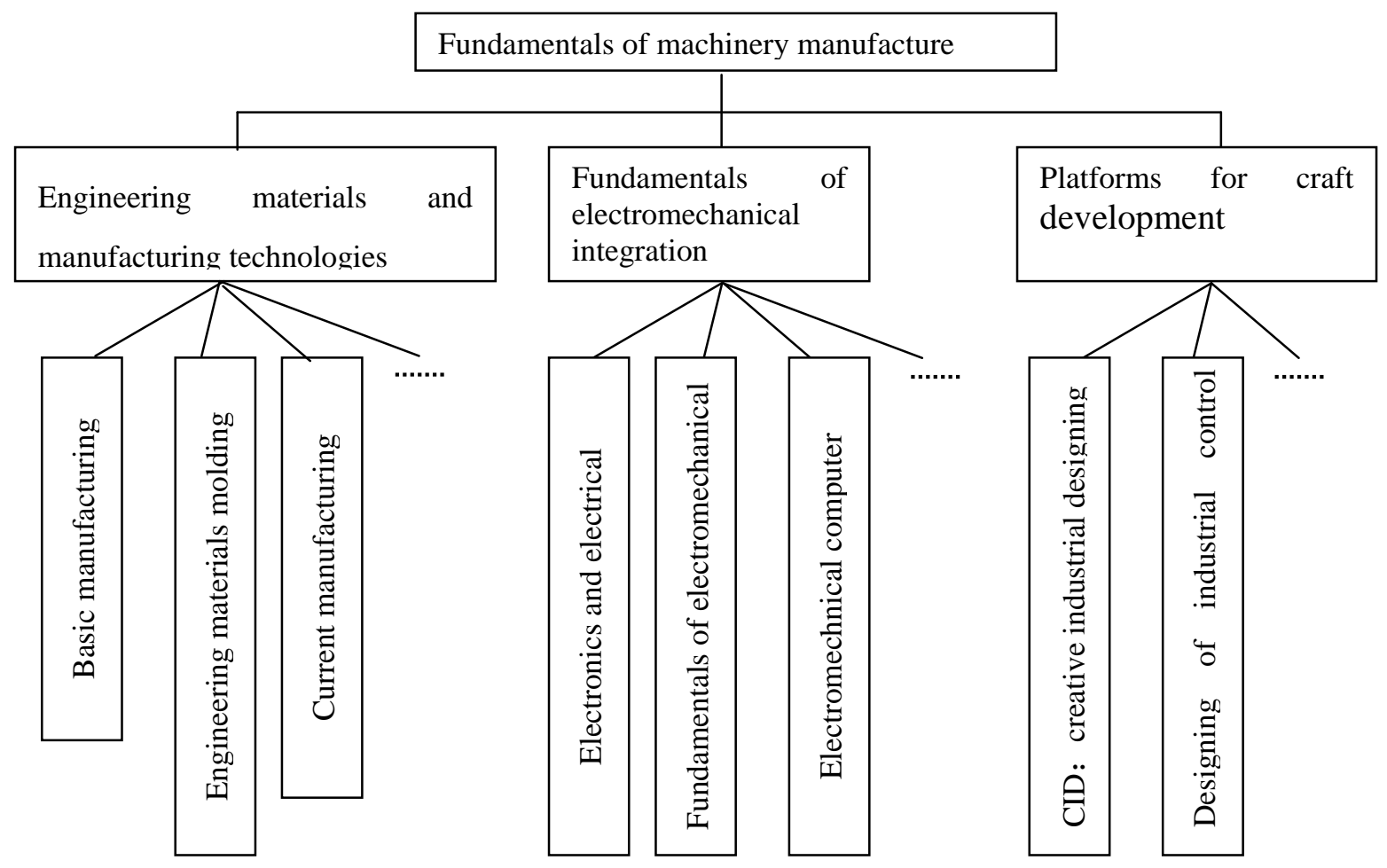

FIGURE I. MODULARIZATION OF THE TEACHING-LEARNING CONTENTS.

\section{DEVELOP DACUM (DEVELOP A CURRICUlA UM) CHART AND DETERMine THE PATHWAY To REALIZE THE CULTIVATION GOALS}

The DACUM chart is a tool to analyze and determine the necessary skills for a particular occupation. On the basis of thorough investigation of what the society and related majors require for a graduate, the DACUM chart helps to determine what the students should master during the learning process of Fundamentals of Machinery Manufacture, including both theoretical and practical knowledge. Then, following these specific goals, it can be decided to what extent the students should learn for a given course, as well as the targets of class learning and practice training. Each of these missions give the students a clear idea what they need to know for a particular skill. For example, for numerical control machining, the students need to learn both theories of numerical control machinery and how to operate, maintain and write programs for numerical control machines. For the theoretical part, the students need to master basic knowledge of electronics and electro-mechanical switching, and for the programming part, the students need to learn computer-aided drawing, craft analysis of the drawing sheet of a part, and CAM. All these knowledge should be included when planning the curriculum for a particular major. By doing so, the students clearly know what they can learn and what skills they will master at each learning stage. If the students want to learn more advanced knowledge, they also know where to find related information.

With clear idea of the learning goals and learning contents, the students can timely feedback the problems they have during the learning process. In this way, the passive 'infusion education' become heuristic education. The students will be more active in the learning-teaching interaction, and the actual education efficiency goes up to the next level. The teacher will evaluate the performance of each student at each learning stage, and integrate their marks into the final records. 


\section{DeVeloping The Study Packages And Itemizing The CUlTivation GOALS}

Development of the study packages is to realize the cultivation goals in the DACUM chart during the whole teaching process. Development of the study packages must coordinate the relationship among the cultivation goals, the teaching contents and the contents to be assessed. Development of the study packages can be divided into four steps:

\section{A. Working Procedure Analysis}

This means analysis of the order of various procedures involved in a particular job. The students are going to be engaged in different occupations after graduation, and each of these occupations has its own specific working procedures. The working procedure can be used to set up the learning process and arrange the learning scenes. The study packages should be established on the basis of actual engineering applications.

\section{B. Analysis of the Combination of Skills}

Professional skills often are related to each other. Analysis of the combination of skills means investigation of the potential help of one skill a student already learned on the learning process of another one. The essential of heuristic education is that, the students should be capable of use one learned skill as a tool to learn another one.

\section{Making the Learning Schedule}

Based on the teaching syllabus, make a reasonable arrangement of the learning process of various knowledge points, coordinate the time needed to master related learning stages, make sure the students can finish their learning task in a timely manner.

\section{Setting up the Study Packages}

The contents of a study package include not only the learning materials such as lecture notes, textbooks and practical guidance books, but also supporting teaching manners such as radios or videos and helpful computer software. The study packages are going to be used mainly by the students, so they should be self-teaching friendly, and the students can easily extract the information they need. In this way, the serial courses of Fundamentals of Machinery Manufacture can be exoteric, easy-to-learn and practical.

\section{Managing The Execution Of The Teaching CONTENTS}

Execution of the teaching contents can be managed by multilayer modules. Based on the cultivation goals, the teaching contents can be divided into several modules, as exemplified in Figure 1. Each direction can be further divided into several sub-directions. This modular education system will significantly facilitate the coordination of various teaching contents, and it can be used to choose related modules for a particular major or cultivation direction, or be used to increase or decrease one or more modules based on changes of the market requirements. For potential industrial technical training centers and related laboratories, this helps to lower the possibility of blind construction.
In summary, using the CBE education mode to guide educational reformation of the serial courses involved in Fundamentals of Machinery Manufacture is helpful to clear the thoughts, so as to make the whole teaching-learning process an integral, coordinated and tightly related one. During the execution of the reformation, we should thoroughly utilize all available or already-had resources, and try various choices during the practice, so we accumulate more and more experience and gradually optimize the process, and finally get to the goals.

\section{REFERENCES}

[1] FangYang, Lehua Qi and Haiguo Ren, "Some ideas about fundamentals of machinery manufacture curriculum reform facing the $21^{\text {st }}$ century”, Journal of Northwestern Polytechnical University (Social science edition), 2000, 20 suppl. issue(66), pp.54-57.

[2] Jianguo Ma, "Using the CBE teaching model reform of fundamentals of machinery manufacture teaching”, Metal Working Research, 2001, 2, pp 3-6.

[3] Gene E. Hall (1976) Competency-based Education, A Process for the Improvement of Education, Prentice-Hall.

[4] John Burke (1989), Competency Based Education and Training, Psychology Press, 1989.

[5] Anne Mette Morcke, Tim Dornan, Berit Eika, Outcome (competency) based education, an exploration of its origins, theoretical basis, and empirical evidence, Advances in Health Sciences Education, October 2013, Volume 18, Issue 4, pp 851-863.

[6] Yong-lin Moon, Education reform and competency-based education, Asia Pacific Education Review, August 2007, Volume 8, Issue 2, pp 337-341.

[7] Thomas Baumann, Dr. Sarah Harfst, Alice Swanger, Gary Saganski, Daw Alwerfalli, Dr. Amy Cell, Developing Competency-based, Industry-driven Manufacturing Education in the USA: Bringing together Industry, Government and Education Sectors , Procedia Social and Behavioral Sciences, Volume 119, 19 March 2014, pp 30-39.

[8] M.Tisch, C. Hertle, J. Cachay, E. Abele, J. Metternich, R. Tenberg, A systematic approach on developing action-oriented, competency-based Learning Factories, Procedia CIRP 7 ( 2013 ) , pp580 - 585. 